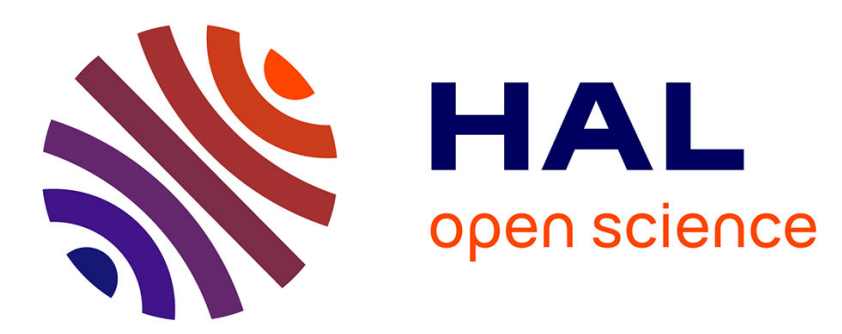

\title{
Measuring and understanding the microeconomic resilience of businesses to lifeline service interruptions due to natural disasters
}

Nina Graveline, Marine Gremont

\section{- To cite this version:}

Nina Graveline, Marine Gremont. Measuring and understanding the microeconomic resilience of businesses to lifeline service interruptions due to natural disasters. International Journal of Disaster Risk Reduction, 2017, 24, pp.526-538. 10.1016/j.ijdrr.2017.05.012 . hal-01631780

\section{HAL Id: hal-01631780 \\ https://hal.science/hal-01631780}

Submitted on 9 Nov 2017

HAL is a multi-disciplinary open access archive for the deposit and dissemination of scientific research documents, whether they are published or not. The documents may come from teaching and research institutions in France or abroad, or from public or private research centers.
L'archive ouverte pluridisciplinaire HAL, est destinée au dépôt et à la diffusion de documents scientifiques de niveau recherche, publiés ou non, émanant des établissements d'enseignement et de recherche français ou étrangers, des laboratoires publics ou privés. 


\section{Measuring and understanding the microeconomic resilience of businesses to lifeline service interruptions due to natural disasters}

(1)

${ }^{1}$ Both authors contributed equally to the paper and are listed in alphabetical order.

${ }^{\mathrm{a}-B u r e a u}$ de Recherches Géologiques et Minières (BRGM), 1034 rue de Pinville, 34000 Montpellier, France

Corresponding author: Marine Grémont - email: m.gremont@brgm.fr

\section{Abstract}

Facing rising natural hazards, urban environments are particularly prone to suffer economic impacts from business interruptions due to disaster-induced lifeline service disruptions. Enhancing the ability of local economies to maintain function and hasten recovery in the aftermath of natural disasters triggers the need to both measure economic resilience and better understand its drivers. Based on a conceptual framework that highlights the peculiarities of resilience with respect to vulnerability and adaptation, this paper develops a scientifically sound operational indicator of the economic resilience of individual businesses to lifeline service interruptions caused by natural disasters. The indicator is constructed so as to compare patterns of economic resilience across firms or events and identify hotspots of poor resilience that public policies should target as a priority. In order to demonstrate its scientific and operational relevance, it is applied to individual businesses located in the Urban Community of Central Martinique (French West Indies). A business survey is used to collect empirical data for two hypothetical equal hazard scenarios leading to the disruption of the drinking water and electricity networks. An econometric analysis then investigates the dependence of economic resilience to a set of individual characteristics such as business demographics and operating characteristics. Results show that businesses are relatively more resilient to drinking water interruptions than to electricity cuts and that turnover and flexibility in both working hours and production processes are significant drivers of economic resilience. We discuss the limitations of this indicator and pinpoint the challenge for future research of isolating pre-existing sensitivity to shocks from overall economic impacts.

Keywords: Economic resilience; indirect impacts; resilience indicator; business interruption; lifeline service disruption; disaster risk reduction.

\section{Introduction}

In upcoming decades, impacts of natural disasters are likely to increase because of both changes in the occurrence and severity of extreme events and changes in the exposure and vulnerability of societies to natural hazards (IPCC, 2014). Meanwhile, the uncertainty of future threats and the complexity of integrated social, technical and economic systems, increase the challenge of performing disaster risk analysis, especially in dense urban environments. Because their results highly depend on uncertain and often unprecedented natural phenomenon, classical risk assessments are likely not to be sufficient to 
provide decision-makers with robust risk reduction strategies. A more pragmatic approach to disaster risk reduction consists in building resilience in socio-ecological systems in order to strengthen their ability to recover and adapt from adverse events of any kind (Linkov et al, 2014). Resilience assessments allow scaling-up the analysis framework so as to both enhance recovery and reduce risk while avoiding thoroughly accounting for the peculiarities of the initial hazard characteristics. As such, they improve upon risk assessments to support decision-making under uncertainty.

Because they are the ultimate decision-makers of economic systems, businesses are a cornerstone in building resilience of local economies. Their resilience, that is their ability to cope with new physical and market conditions and maintain operations under stress, is crucial in the aftermath of extreme events. They ensure the provision of goods and services that are essential to sustain livelihoods and secure incomes for households, hastening thereby the recovery of entire communities. Measuring and understanding their resilience to disaster risks is an important contribution to design efficient resilience enhancement strategies (Smit \& Wandel, 2006; Vincent, 2007). However, any attempt to measure the economic resilience of businesses requires understanding their recovery process, which in turn depends upon the economic impacts they are likely to suffer.

Economic impacts of natural disasters fall into two broad categories: direct impacts, which arise directly from physical impacts, such as the cost of replacing a damaged building, and indirect impacts which are second-order downstream effects that result from the diffusion of physical impacts across the wider economic system, such as production loss due to water shortages caused by a damaged pipe or increased production costs due to health related absenteeism (Hallegatte et al., 2011; Pelling et al., 2002; Tierney, 2007). Because they have a straightforward and tangible effect on the economy and are mostly covered by private insurances, it is standard practice to assess direct economic impacts in the aftermath of natural disasters (André et al. 2013). Indirect economic impacts are however more complex to capture. Hallegatte \& Przyluski (2010) provide a few explanations for this shortcoming, among which the longer time span and larger spatial scale of indirect impacts or the fact that they vary across sectors and economic agents. Yet, in the long-run, indirect impacts add to total economic impacts of disasters to an extent that often exceeds direct physical damages (Rose \& Liao, 2005; Tierney, 1997). Thus, capturing these indirect impacts is of prime importance to measure economic resilience in its entirety.

The literature on the assessment of indirect impacts and economic resilience of businesses is scarce. Hallegatte (2008) developed an approach based on input-output tables to model economic impacts through input supply and demand variations across economic sectors, accounting for propagations and adaptive behaviors. Brozovic et al. (2007) developed a methodology that consists in compiling sector specific (typology dependent) demand functions from different sources in order to assess the total costs of water lifeline interruptions following severe earthquakes in California both for business and residential water users. These approaches can be characterized as top-down or standardized normative approaches that disregard the particularities of individual businesses within a sector. As pointed out by Kajitani \& Tatano (2009), such classical estimations of economic damages to production losses account for restrictions of production capacity in an adhoc manner but do not integrate vulnerability and resilience of businesses to assess production capacity losses, although Hallegatte (2008) attempted to integrate adaptive behaviors in its approach. This is partly due to the lack of a common understanding of the multidimensional nature of economic resilience that differs from - but also encompasses aspects of - vulnerability and adaptation. Omitting that resilience is not only sector dependent but rather depend on individual characteristics that reflect the organization of the firm and affect its ability to recover from a shock leads to frequent misinterpretations. 
This paper presents a complementary approach to standard, sector-typology based approaches described above in order to assess and investigate the processes and factors underlying individual economic resilience of businesses. Its ambition is to make the best use of the available theory in a very pragmatic goal: measuring and understanding the resilience of businesses in order to provide public policies with recommendations for building resilient economies. We first develop an explicit conceptual framework of the economic resilience of individual businesses that integrates and clarifies the relationships between resilience, adaptation and vulnerability. We then develop an aggregated indicator of economic resilience that addresses some of the current scientific and technical obstacles regarding the measurement of economic resilience at individual scale. The strength of our methodology lies in its ability to scientifically ground an operational measurement of microeconomic resilience that accounts for both the individual ability to cope with potential impacts and the timing of recovery. As an illustration, the indicator is then applied to businesses of the Urban Community of Central Martinique. Located in the French West Indies, this overseas territory encompasses many factors of vulnerability commonly censed in isolated islands (IPCC, 2014; Pelling \& Uitto, 2001). Most of its infrastructures and activities are concentrated on the coastline which is subject to increasing natural hazards due to climate changes (e.g. erosion, submersion, rising sea-level) (Hess et al., 2008; Pelling, 2010; UNFCC, 1992; UNISDR, 2005). Moreover, insularity makes lifeline services particularly prone to cut-offs and outages, especially in the event of a natural disaster. As for economic impacts, they are likely to be significant because the economy of the French West Indies is mostly made of small businesses, often thinly capitalized and individually owned, that do not benefit from strong support functions to help them anticipate and cope with potential impacts.

This research focuses on the microeconomic resilience of businesses to lifeline service interruptions, and as such, does not account for macroeconomic effects of natural disasters that pertain to the overall systemic resilience of the economy. However, the concepts and indicators produced may contribute to adapt production functions in macroeconomic models such as CGE models as suggested by Rose \& Liao (2005) who argue that classical models do not account for resilience and as such, tend to either overestimate (e.g. when adaptations are not accounted for), or underestimate (e.g. when a systematic return to equilibrium is considered after a long period of time), the effects of natural hazards on the economy. Concentrating on microeconomic processes allows our analysis to focus on the intrinsic ability of individual businesses to recover and adapt to a given degraded situation, disregarding the characteristics of the event that generates damages and indirect market effects such as dropping demand or increasing supply prices. It focuses on private businesses that are operated for profit, as opposed to public sector and non-profit organizations. This includes all types of business proprietorship, irrespective of their sector, size and turnover.

The present paper is organized as follows. We develop a conceptual framework for economic resilience and describe its theoretical foundations in section 2 . We then propose in section 3 an original methodology to measure and assess the economic resilience of individual businesses. Results of the application of this indicator-based approach are presented in section 4. In particular, the socioeconomic drivers of economic resilience are investigated using a linear regression model. Section 5 discusses the interests and the limits of our methodology and section 6 concludes by presenting a set of future perspectives to this work.

\section{Conceptual framework for the economic resilience of individual businesses}

Building on existing literature, we suggest a conceptual framework that highlights the composite nature of economic resilience at the microeconomic level (Fig. 1). This framework clarifies the 
relationships existing between vulnerability, adaptation and resilience. In doing so, it provides an analytical basis that is consistent with approaches developed in both risk and economic conceptual models (Sedan et al, 2013; Aulong et al, 2011; Hallegatte \& Przyluski, 2010).

\subsection{Vulnerability}

Natural disaster risks result from the interaction of (1) a hazard, that is the potential occurrence of a natural or human-induced physical event that may cause damage, harm or adverse effects, (2) the exposure, that is the presence of stakes (e.g. people, assets, resources) in places and settings that could be adversely affected; and (3) the vulnerability, which is the propensity or predisposition of individuals, communities and the environment to be adversely affected (IPCC, 2014). Focused on hazard as the triggering mechanism, vulnerability is commonly defined in the literature on disaster risks as the sensitivity of exposed elements to hazards (Papathoma-Köhle et al., 2011) or as the degree to which a system is likely to experience damages due to its exposure to a hazard (Turner et al., 2003). Social science literature offers a wider vision of the concept, including also non-hazard related forces (contextual parameters) influencing vulnerability (Adger, 2006; Fussel \& Klein, 2006; Gallopin, 2006; Kelly \& Adger, 2000). The last IPCC report ${ }^{1}$ recognizes vulnerability as a multidimensional propensity or predisposition that depends not only upon the character and intensity of the hazard to which a system is exposed, but also upon its lack of capacity to adapt, its sensitivity or susceptibility to harm, and its social, economic and institutional organization and development pathways (IPCC, 2014). This interpretation acknowledges that, by enhancing coping capacities, adaptation is a mean to reduce vulnerability (Pelling, 2010), and that vulnerability is directly connected to the intrinsic characteristics of individuals and communities (Bassett \& Fogelman, 2013; Birkmann, 2006; Kelly \& Adger, 2000; IPCC, 2012). In this paper, we understand vulnerability as a multidimensional pre-existing condition driven by both hazard and non-hazard related factors that jointly determine the predisposition to be adversely affected by a disaster. In line with recent literature (Angell and Stokke, 2013; Birkmann et al., 2013; Menoni et al., 2002; Pascale et al., 2010), we split vulnerability into three main dimensions: physical (or material) vulnerability that relates to the physical resistance of an element exposed to a hazard (e.g. the resistance of a building to an earthquake); systemic (or functional) vulnerability that depends on the functional organization of a system (e.g. the importance of a road section in the overall transportation network given its spatial distribution and actual use by city-dwellers); and socioeconomic vulnerability that pertains to the intrinsic socio-economic characteristics and abilities of individuals (e.g. the propensity of a business to get help from its professional network).

\section{3}

\subsection{Adaptation}

Adaptation is the process of adjustment to actual or expected disasters or stresses and their effects (IPCC, 2014). Spread through climate change policies, the concept of adaptation has been largely dissected and debated in the literature (Bassett \& Fogelman, 2013; Pelling, 2010; Smit \& Wandel, 2006). Together with mitigation, it is one of the two main strategies used to reduce disaster risks. However, unlike mitigation that focuses on reducing the root cause of a potential upcoming disaster (i.e. before it occurs, such as the strengthening of buildings), adaptation actions apply to both actual and expected events and may be implemented before, during and after a disaster. Depending on their intent, scale, timing and purpose, they can be classified into many categories (e.g. incremental versus transformational, private versus public, hard versus soft, autonomous versus planned) (Basset et al., 2013; Biagini et al., 2014; Hallegatte, 2009; Park et al., 2012; Pelling, 2010; Smit et al., 2000; Tompkins \& Eakin, 2012). In particular, their timing of implementation allows distinguishing anticipatory or pro-active adaptations that are deliberate decisions to prepare for potential effects (e.g.

\footnotetext{
${ }^{1}$ The advances in conceptualizing vulnerability between IPCC's Third and Fifth Assessment Reports are a noteworthy evidence of the progress the scientific community achieved in understanding the complexity of this concept.
} 
having a generator at disposal to cope with potential power cuts, i.e. ex-ante) from reactive adaptations that are carried out in response to a specific event (e.g. buying a generator once the power is off, i.e. ex-post) (Fankhauser et al., 1999). Despite the diversity of their definitions and rationales, most scientists agree that adaptation actions are manifold, both technological and behavioral (incl. organizational), and that they aim at reducing risks and fostering coping capacities. In our conceptual framework, adaptation is defined as any adjustment or transformative process that allows either preevent risk reduction, in-time or post-event risk coping. We consider as crucial the distinction between pro-active and reactive adaptations, with pro-active adaptations being a driver of the wider concept of vulnerability.

\subsection{Resilience}

Resilience results from both adaptation actions and vulnerability. Often described as the opposite of vulnerability, the concept of resilience has recently become a buzzword in the disaster risk literature. Used in various ways by ecological, psychological or social sciences to reflect the ability of a system to respond to disturbances, self-organize, learn and adapt, the concept is subject to multiple interpretations (Alexander, 2013; Folke, 2006; Manyena, 2006; Reghezza-Zitt et al. 2012; Rose, 2009; Saunders \& Becker, 2015; Turner, 2010). A review of the recent literature on resilience can be found in Hosseini et al. (2016) and Bergström et al. (2015). IPCC describes resilience as the capacity of social, economic, and environmental systems to cope with a hazardous event, responding or reorganizing in ways that maintain their essential function, identity, and structure, while also maintaining the capacity for adaptation, learning, and transformation (IPCC, 2014). Thus, resilience takes place in the post-disaster response and recovery phases. It is driven by adaptive capacity since it relies on actions carried out to reduce the impacts of specific events or to transform to better cope with these events. But it differs from vulnerability in that it pertains to post-disaster outcomes and only becomes operational in the aftermath of an event, when vulnerability characterizes a pre-existing condition. However, resilience can also be strengthened prior to a disaster by pro-active measures that increase the capacity of a system to cope with upcoming effects. To clarify this time-related duality, Rose (2009) identifies two components of economic resilience: inherent and adaptive resilience. Inherent resilience pertains to abilities that were part of the system prior to disasters. It is resilience already built in the system (e.g. the ability to use inventories in case of supply outages). Adaptive resilience arises out of ingenuity under stress and pertains to decisions made during and in the aftermath of disasters (e.g. the ability to substitute inputs given newly available materials) (Rose, 2004; Rose et al., 2013; Tierney, 2007). Together, inherent and adaptive resilience enable individuals and communities to avoid potential losses by returning as quickly as possible to an equilibrium state, may it be steady or dynamic. Based on the definition proposed by Rose (2009), we define economic resilience as the capacity to absorb an initial shock through pro-active adaptation, and to respond and adapt afterwards through reactive adaptation, so as to maintain function and hasten recovery, as well as to be in a better position to reduce losses from future disasters. This definition is consistent with Birkmann et al. (2013) who differentiate the concept of resilience into a coping part that deals with the 'here and now' capacity and resort to a set of actions currently available to those at risk and an adaptation part that deals with the longer-term process of learning and reorganizing. However, it goes behind by considering that the equilibrium state in which the system returns may or may not be the pre-existing (or current) state. This echoes the recent distinction made by Manyena et al. (2011) between bouncing back and forward after a shock. Initially used as a bounce back notion measuring the propensity of a system to return to its previous equilibrium in order to preserve its overall stability (Holling, 1973; Timmerman, 1981), resilience can also be considered as a bounce forward notion allowing a system to come back stronger and move on by rebuilding itself and hereby changing from the original state (Manyena et al., 2011). 
Building on the literature background presented upfront, we suggest a conceptual framework that provides an analytic setting for resilience assessments at individual scale (Fig.1). Our framework highlights the essential place of time in the resilience concept. It distinguishes two periods in coping with disaster risks: (i) the short term, also called immediate aftermath, when impacts of disasters are strongly felt and coping capacity depends on the inherent resilience already built in the system that relies upon pre-existing vulnerability and pro-active adaptation measures, (ii) the medium term, also called reactive period, when the business has organized and implemented measures to deal with the impacts and where the adaptive resilience expresses. Adaptive resilience depends upon the magnitude of the impacts felt in the short to medium terms as well as the reactive adaptations undertaken in response to these impacts. Overall long-term economic resilience is the aggregated inherent and adaptive resilience. In this paper, we focus on the economic dimension of resilience. Other types of physical or systemic resilience could also be investigated using the same framework. However, this work falls outside the scope of this paper.

\section{Fig.1. - Approximately here}

\section{7}

\section{Material and method}

\subsection{Background on indicators of economic resilience}

Measuring economic resilience is not a trivial exercise. It faces three main difficulties. First, resilience is a composite measure of adaptation actions, pre-existing vulnerability and actual impacts on business activities, which in turn depend on the magnitude of the hazard and the exposure of the business. Therefore, any attempt to provide a complete and integrated resilience indicator should encompass its multidimensional nature. Second, it pertains to characteristics and actions existing and occurring before, during and after a disaster. Therefore, indicators should account for the dynamic of the process. Third, resilience is driven by individual socio-economic characteristics and behaviors, some of which are made manifest only when individuals are faced with a disaster. Relevant indicators should account for individual choices.

Two main approaches can be distinguished in building business-level economic resilience indicators. A first approach consists in characterizing an indicator of resilience with an apriori (deductive) approach. It calculates indexes based on a set of publicly available observed characteristics of firms. Eidsvig et al. (2014) and Oxford Metrica (2015) built business resilience to supply chain disruption indexes at country level combining economic, risk quality and supply chain factors, each described using three drivers. The nine drivers combined with equal weights enable to calculate a resilience index. However, these approaches cannot account for post-disaster reactive adaptations nor for differences in individual firm behaviors, and as such do not fit our concept. A second literature strand relies on a more empirical approach and consists in calculating a microeconomic economic resilience indicator as a measure of the ex-post economic impact of disasters. Such an approach has been developed by Rose (2009). Differentiating static economic resilience defined as the ability to maintain function after a shock from dynamic economic resilience defined as the speed at which an entity recovers from a shock, Rose (2009) suggests measuring direct static economic resilience (DSER) as the extent to which actual change in business output deviates from its likely maximum in the aftermath of a given disaster:

$$
D S E R=\frac{(\% \Delta D Y m-\% \Delta D Y)}{\% \Delta D Y m}
$$

With:

- $\% \triangle D Y m$, the maximum percent change in direct output that could result from a disaster if businesses had no coping capacity; 
- $\% \Delta D Y$, the actual percent change in direct output that reflects and integrates the resilience options that firms implemented to minimize impacts.

This indicator has been adopted by various authors (Chen et al., 2015; Cox et al., 2011). Its main challenge involves quantifying $\% \triangle D Y m$ as this is a theoretical figure that is per se not measurable, unless in extreme fully destructive disasters where the maximum percent change is $100 \%$ (e.g. firms going out of business after the 9/11 attacks in the United States) (Rose \& Brock, 2010; Hosseini et al, 2016). To overcome this pitfall, Kajitani and Tatano (2009) define a resilience indicator as the ratio of production capacity during the impacted period over the baseline production capacity. Although straightforward to compute, this ratio does not account for the vulnerability component of the resilience since it does not differentiate businesses that are initially little impacted from those that are strongly impacted but whose adaptations succeeded in reducing overall impacts compared to a baseline scenario. A misinterpretation with a direct relationship between resilience and production capacity would tend to characterize a firm as resilient if it had nothing to do in the face of on event (i.e. a firm that is not vulnerable). As such, this indicator does not fully comply with the definition of the economic resilience consisting in emphasizing on the capacity to recover after an event and to reorganize. Darnhofer (2010) suggests to measure economic resilience in the farming sector as the inverse of the cost incurred by the firm because of the event. This is consistent with the view that vulnerability is the opposite of resilience and supports the idea of taking a monetary impact on the output as a measure of resilience although it does not account for the multidimensional nature of the process.

One of the main limits of these measures of economic resilience is that they integrate vulnerability and resilience components with a global impact measure, which does not allow isolating the ultimate economic impact from the inherent vulnerability component. This illustrates the difficulty to maintain the two concepts of vulnerability and resilience separate as soon as it comes to metrics. In our perspective, this is of interest to really understand the process of individual resilience whose added value as an analytical concept stems from its ability to capture not only the predisposition to be affected but also the rebound capacity when faced with a destructive event.

\subsection{Metrics of economic resilience}

Based on the previous literature review, we suggest measuring economic resilience (ER) of individual businesses to lifeline service interruptions with an integrated indicator that accounts for long-term impacts and pre-existing vulnerability separately. ER is measured as:

$$
\left\{\begin{array}{c}
E R=1-\frac{L t I}{S} \\
L t I=S t I \times t \times \sigma \\
S t I=\Delta Y+O M I+N M I \\
E R>0
\end{array}\right.
$$

With:

- $\Delta Y$, the percentage change in business turnover during the event;

- OMI, the other market impacts incurred by businesses during the event (e.g. increasing production costs, penalties dues to non-compliance with commercial contracts);

- $\quad N M I$, the non-market impacts incurred by businesses during the event (e.g. increasing painfulness of work, damages to reputation, stress of the workforce);

- $\quad t$, the recovery period, that is the length of time that separates the occurrence of the event from the return to normalcy of business activities; 
- $\sigma$, the equilibrium state, that is an indicator of the new level of activity reached by businesses in the long-run;

- $S$, the sensitivity, that is the level of dependence of business activities to the lifeline service under study ;

- $\quad L t I$, the long-term economic impacts of the disaster;

- StI, the immediate (short-term) economic impacts of the disaster.

Here, economic resilience is defined as an aggregated indicator of the overall economic impacts suffered by a business following a disaster, given its pre-existing vulnerability to the disaster. Its calculation requires computing two economic impact indexes successively: (i) an aggregated immediate economic impact index (StI) that accounts for the strength of the impact during the disaster and encompasses three indicators (change in turnover, other market impacts and non-market impacts), and (ii) an aggregated long-term economic impact index (LtI) that accounts for the overall impact of the disaster once business operations returned to normalcy and encompasses three indicators (immediate economic impacts, recovery time and equilibrium state). StI includes both market and non-market impacts. Amongst market impacts, demand-side effects resulting in changes in turnover $(\Delta Y)$ are distinguished from supply-side effects resulting in additional costs for businesses (i.e. monetary damages) (OMI). ER also accounts for pro-active and reactive adaptation actions. Since it depicts the effects of the disaster, given the inherent characteristics of the business, the StI component already captures the effect of pro-active adaptation actions. As for reactive adaptations, we consider that they allow reducing the duration of the impacts which is captured by the recovery time component $(t)$. The nature of the equilibrium state reached by businesses once their activity has returned to normalcy is captured by an indicator $(\sigma)$ that differentiates bouncing back from bouncing forward profiles. When understanding and assigning values to these metrics, a particular attention has to be given to avoiding double counting (see also how this is handled for a specific case in our illustration). To avoid double counting of pro-active adaptations that are already embodied in the resilience indicator through $S t I$, we only keep in the formula the sensitivity component $(S)$ of vulnerability, sensitivity being defined as the vulnerability from which pro-active adaptations are removed. In our case, sensitivity is approximated by the root cause of the impact, namely the level of dependency of business activities to lifeline services, disregarding any pro-active adaptation that could have been implemented to reduce this sensitivity (e.g. having a water tank at disposal in case of water outages). Double counting may also arise from overlapping between $\triangle Y, N M I$ and $O M I$. For instance, some non-market impacts may affect turnover (e.g. increasing stress of the workers may impact productivity). However, all these components are isolated in the formula in order to acknowledge that the impact that they capture should be accounted for in their essence (e.g. stress is per se a "damage" to the employee) and not only because they have an effect on turnover. Figure 2 illustrates the performance profiles of businesses during and after an event in a dynamic way. It enables to illustrate several parameters of the economic resilience indicator and relates to the conceptual framework presented upfront.

In order to demonstrate the interest of the indicator in understanding factors of resilience, we develop two econometric models that investigate the dependence of economic resilience to a set of individual characteristics (explanatory variables). It is assumed that the economic resilience of individual businesses depends on their demographics (e.g. economic sector, turnover, number of employees), their operating characteristics (e.g. indebtedness, inventories), their owner's characteristics (e.g. age, level of education), and the pro-active and reactive adaptations they are likely to implement when affected by a disaster. 


\subsection{Illustration}

\subsubsection{Case study presentation}

Economic resilience was assessed for individual businesses of the Urban Community of Central Martinique (UCCM). Martinique is an overseas region of France located in the Caribbean Sea and part of the archipelago of the French West Indies. Due to its geographic location in the Central Lesser Antilles subduction zone, its volcanic origin and tropical climate, it is particularly prone to natural disasters; in particular earthquakes, hurricanes, landslides, floods and volcanic eruptions. In 2007, hurricane Dean caused major damages to buildings and infrastructures. Its total cost was estimated to more than $500 \mathrm{M} €$, including about $102 \mathrm{M} €$ attributable to the repair of networks and infrastructures (mostly electricity supply and roads), and $97 \mathrm{M} €$ to business losses in the industrial, commercial and craft sectors, with many businesses suffering temporary operating losses of one to two weeks (Babre et al., 2007). Later the same year, an earthquake of magnitude 7.4 on the Richter scale occurred on the island. Damages were mostly material and included several building collapsing and power outages. Besides its geographic location, Martinique is also particularly vulnerable to disaster risks due to the concentration of most of its population, infrastructures and economy within the relatively small perimeter of the UCCM. Located on the Caribbean coast, the UCCM encompasses four municipalities and accounts for $42 \%$ of the population and $56 \%$ of the total number of businesses registered on the island. Its economy is mainly made of small enterprises, with no or very few employees, exercising mostly in the services, tourism, transport and construction sectors, and focused on local markets ${ }^{2}$. Moreover, the UCCM territory concentrates many critical lifelines and infrastructures whose functioning is crucial to small businesses. Yet, insularity makes those services particularly prone to cut-offs and outages, especially in the event of a natural disaster.

\subsubsection{Data collection}

Because our approach requires aggregating a set of observed variables to build an indicator, it involves recovering a large range of business-level information. Neither public statistical nor private insurance databases provide such disaggregated and specific data. Therefore, we resort to an ex-ante business survey that is particularly fitted to gather site-specific information on individual businesses. It also enables collecting data for a hypothetical equal hazard scenario - here, the disruption of lifeline service networks - which allows comparing economic impacts disregarding hazard exposure. This would not be possible with a post-event survey that would collect information from firms that were differently impacted because they were originally differently exposed to the hazard according to their geographic location.

Our methodology includes a two-step data collection process consisting in a series of face-to-face interviews with local decision makers, natural hazard experts and individual businesses, and in the Internet dissemination of an on-line questionnaire to individual businesses (sees Appendix for details). Interviews were carried out in order to fine-tune the design of the questionnaire in light of empirical information. They helped characterize how network interruptions impact firm activities (e.g. which technical, economic and organizational processes are likely to be affected at firm level) and pre-

\footnotetext{
${ }^{2}$ The important share of small businesses in Martinique results from the island's high unemployment rate (about $20 \%$ in 2014), especially among young people, whose struggle to find a steady employment often leads them to start their own company.
} 
identify a set of adaptation actions likely to be implemented by businesses to cope with these impacts and recover from the shock.

The questionnaire focused on the economic impacts resulting from the interruption of lifeline services provided by critical networks in the event of natural disasters. In line with recent local events, two interruption scenarios were exposed to respondents disregarding the natural hazard causing the interruption as well as potential side and macroeconomic effects: an interruption of the drinking water network for one week and an interruption of the electricity network for two days. The questionnaire aimed to collect data in order to (i) calculate individual economic resilience, and (ii) understand the drivers of economic resilience that are embodied in the peculiar characteristics of businesses (e.g. economic sector, annual turnover, geographic location, diversification of activities) and likely to explain their ability to cope with network interruptions. It was designed using Limesurvey ${ }^{3}$, a free and open source on-line survey application. Because it is an eco-friendly, inexpensive, easy to administrate and use process, the questionnaire was disseminated exclusively on the Internet. It was e-mailed from July to October 2015 to businesses registered by three local economic institutions and to members of twenty representative local business associations ${ }^{4}$. It was also publicized on social media (Facebook®, Viadeo ${ }^{\circledR}$ and LinkedIn $\left.{ }^{\circledR}\right)$. To maximize the response rate, a lottery incentive was eventually added to the survey ${ }^{5}$.

Questions were designed so as to recover each component of the resilience indicator. Every metric is thus directly recovered from a question of the survey (Table 1). Indicators were constructed as follows:

- The change in turnover $(\Delta Y)$ is directly provided by respondents and expressed in percentage of baseline turnover over the length of the event ;

- The recovery time (t) is the ratio of the duration of the impacts to the duration of the event, both quantities being expressed in days ${ }^{6}$;

- The equilibrium state $(\sigma)$ is a coefficient that is 1 if the level of activity of the business suffered no impact after one year (bounce back profile), 0.5 if activity increased (bounce forward profile) and 1.5 if activity decreased;

- The other market impacts $(O M I)$ and non-market impacts $(N M I)$ are qualitative weighted indicators computed as $\sum_{i} I_{i} * w_{i}$, with $I_{i}$ a binary variable taking 1 if impact $i$ was suffered by the business and 0 otherwise, and $w_{i}$ a weighting factor accounting for the importance of each impact $i$ on business operations (Table 1);

- The sensitivity $(S)$ is a qualitative weighted indicator computed as $\sum_{a} S_{a} * w_{a}$, with $S_{a}$ a binary variable taking 1 if the service is used for the type of activity $a$ (e.g. network water used for production, sales, well-being) and 0 otherwise, and $w_{a}$ a weighting factor accounting for the importance of each activity $a$ on business operations (Table 1).

\footnotetext{
${ }^{3}$ LimeSurvey: An Open Source survey tool /LimeSurvey Project Hamburg, Germany. http://www.limesurvey.org

${ }^{4}$ Based on public data, a particular attention was paid when selecting business associations in order to target similarly each economic sector so as to ensure that the sample be representative of the general structure of the case study economy.

${ }^{5}$ Respondents that would entirely fill the questionnaire were offered to participate in a lottery selecting randomly 30 winners of a Guide to the Local Geological Curiosities whose retail price is $19 €_{2015}$.

${ }^{6}$ Here, we use a ratio in order to compare two events with different durations. If one was to analyze resilience among companies for a unique event, the sole use of the duration of the impact would be sufficient to capture recovery time. For the present case study, the use of a ratio allows differentiating the relative higher resilience of a business that suffers damages for a week after a one week water shortage from the lower resilience of a business that suffers damages for a week following an only two days electricity blackout.
} 


\section{Results}

\subsection{Description of the sample}

Our sample contains 108 individual businesses whose main characteristics are presented in Table 2 . Microenterprises - less than 10 employees and an annual turnover inferior to $2 \mathrm{M} €$ - account for $64 \%$ of the sample, half of which are less than 8 years old. The service sector represents $80 \%$ of the sample. Respectively $74 \%$ and $94 \%$ of businesses depend on the drinking water and electricity networks for their operations. Interestingly, only $40 \%$ of businesses own their buildings which are also, for $35 \%$ of the sample, the ordinary residence of business owners. In line with the peculiarities of the UCCM economy, businesses are rather small enterprises, often thinly capitalized and individually owned. However, it has to be noted that our sample is quite modest with regard to the 29000 businesses recorded in the perimeter of the UCCM in 2014. Therefore, this case study only aims to illustrate our method and the reader should be aware of the strong limits of our results as they are inferred from a small data set.

A set of 19 adaptation actions either currently implemented by businesses or likely to be implemented in the aftermath of lifeline service interruptions was identified through face-to-face interviews and assessed in the survey (Fig.3). Pro-active adaptations include inventories that enables keeping on producing even in case of default of the supplier, business interruption insurance, risk management procedures, membership in professional groups and well-functioning substitution solutions to the service network (e.g. private well for drinking water, power generator for electricity). During and after the shutdown, reactive adaptation actions are related to both supply (e.g. purchasing bottled water, changing procurement processes) and production activities (e.g. relocating operations, lengthening working hours). Although their relative frequency of implementation depends on the shutdown scenario investigated, all businesses but one already set up at least one pro-active adaptation and most of them would adopt both reactive and pro-active adaptations when faced with lifeline service interruptions. Owning a substitute to the electricity network is the most frequent pro-active adaptation implemented by businesses while the most frequent reactive adaptations in both scenarios are related to modulating working hours.

\section{Fig.3. - Approximately here}

\subsection{Calculation of economic resilience indicators}

Economic resilience of businesses as defined by (1) requires computing several indicators from raw data of the survey that are transformed according to the details presented in section 3.3. Results are summarized in Table 1 and 2. They apply to both the drinking water network shutdown (DWNS) and the electricity network shutdown (ENS) scenarios. Since the objective is to assess economic resilience with regard to lifeline service interruptions, indicators are computed only for businesses whose activities depend on the considered service ${ }^{7}$.

Table 1. - Approximately here

\footnotetext{
${ }^{7}$ The sample does not contain complete data for all the variables required to compute economic resilience (some stem from non-mandatory questions of the questionnaire). Therefore, although the activities of respectively 80 and 102 businesses depend on drinking water and electricity, only 72 and 93 observations are used to assess economic resilience to DWNS and ENS.
} 
Most businesses declare that they would face a decrease in turnover during the interruption $(51 \%$ of businesses during the DWNS and $76 \%$ during the ENS). On average, turnover loss compared to baseline turnover over the length of the event would reach $21 \%$ for the DWNS, that is on average $3320 €_{2015}$ per impacted business, and $32 \%$ for the ENS, that is on average $3440 €_{2015}$ per impacted business $^{8}$. No business would report an increase in turnover, neither during nor after the interruption.

\subsubsection{Other market impacts $(O M I)$}

Apart from changes in turnover, the other market impacts incurred by businesses that are investigated in the questionnaire include production interruptions, sales interruptions, increasing production costs, penalties due to non-compliance with commercial contracts and other impacts on revenues. Respectively $60 \%$ and $64 \%$ of businesses would incur at least one of these market impacts during the DWNS and the ENS. Using the weighting factors presented in Fig.3, OMI ranges on a scale from 0 to 9. On average, it is slightly higher for the ENS (2.3) than for the DWNS (2.0).

\subsubsection{Non-market impacts $(N M I)$}

Non-market impacts vary greatly according to the scenarios. For instance, the ENS would lead to delays in the supply chain for half of businesses, against only $21 \%$ following the DWNS. Overall, more than two third of businesses would suffer disruptions in their organization (e.g. drudgery of work, waste of time) in both scenarios. On a scale of 0 to $12, N M I$ reaches on average 5.1 for the ENS and 3.8 for the DWNS.

\subsubsection{Recovery time $(t)$}

With $83 \%$ of businesses returning to normalcy after the week that would last the DWNS and only 59\% after the two days of the ENS, the recovery time is relatively longer for the ENS than for the DWNS. This means that in the long-run, the longer interruption for the DWNS than for the ENS does not outweigh the relative stronger overall immediate economic impacts when faced with electricity outages. Since $t$ depends on the duration of the event, its scale varies according to the scenarios. It ranges from 1 to 4 for the DWNS and from 1 to 8 for the ENS.

\subsubsection{Equilibrium state $(\sigma)$}

A significant share of businesses would not return to their initial level of activity after one year. Respectively $43 \%$ and $17 \%$ of businesses have a bounce back profile for the DWNS and the ENS, while only one business presents a bounce forward profile for the ENS. Both the recovery time and the equilibrium state indicators suggest a stronger struggle to return to normalcy when faced with electricity outages.

\subsubsection{Sensitivity $(S)$}

Scores of sensitivity highlight that businesses resort more to electricity for operating activities than to water. When $79 \%$ of businesses use drinking water for current use of their staff, only $49 \%$ use electricity for that purpose. Conversely, when $67 \%$ of businesses resort to electricity for production and sales, they are only $39 \%$ to resort to drinking water to this end. As a consequence, overall sensitivity is higher for the ENS than for the DWNS, with scores of respectively 7.8 and 5 on a scale of 0 to 16. This means that by construction, since sensitivity is the denominator of the economic resilience indicator, if a business suffers a similar aggregated long-term economic impact in both

\footnotetext{
${ }^{8}$ The average turnover of businesses that declare they would be impacted by the DWNS is higher than the average turnover of businesses that declare they would be impacted by ENS, which explains the small difference between turnover losses induced by the DWNS and the ENS.
} 
scenarios, it will be considered as more resilient to the ENS than to the DWNS, because it would have managed to overcome its relative higher pre-existing sensitivity to electricity outages than to water shortages.

\subsubsection{Economic resilience $(E R)$}

Economic resilience is computed on a scale of 0 to 100. It reaches on average 86 for the DWNS and 75 for the ENS. The stronger resilience of businesses to the DWNS is mainly due to the contribution of the long-term economic impacts that is about three times less for the DWNS than for the ENS. Over the whole sample, the higher sensitivity to ENS is not sufficient to counterbalance the strength of its economic impacts that result in smaller economic resilience of businesses to electricity outages. When both events are considered, aggregated economic resilience of businesses is 80 . With regard to these indicators, business profiles are quite diverse, with profiles such as high sensitivity/low impacts and low sensitivity/ high impacts fairly represented in the sample, and only a small, but significant, correlation between the economic resilience to ENS and DWNS.

Table 2. - Approximately here

\subsection{Insights into the drivers of economic resilience to drinking water interruptions}

The limited size of the sample prevents us from examining properly all the potential drivers of economic resilience for which data were gathered through the survey. Explanatory variables were selected based on a literature review on the determinants of the economic resilience of individual businesses to natural disasters (Alesch et al., 2001; Asgary et al., 2012; Boarnet, 1996; Brown et al., 2015; Henriet \& Hallegatte, 2008; Kroll et al., 1991; Rose, 2009; Rose et al., 2013; Tierney, 1997 and 2007; Webb et al., 2002) and through face-to-face interviews. They can be classified into three categories: socio-economic characteristics, proactive adaptations and reactive adaptations.

The econometric models are presented in Table 3. Both models are multiple linear regressions. Model A is an extended model that tests multiple drivers. Model B is a reduced version of Model A. Results show that although annual turnover and number of employees are obviously correlated, they have an opposite effect on economic resilience since it declines with the number of employees and rises with annual turnover. This validates that the less workers there are in the firm, the more flexible the organization is, which eases adaptation and fosters resilience. Turnover is a factor of economic resilience, as previously pointed out by many authors (Chang et al., 2003; Rose et al., 2013, Tierney, 1997 and 2007; Webb et al., 2002). Small businesses are more likely to operate with less cash flow which hinders the recruitment of external organizational or logistical support functions to help them anticipate and cope with potential impacts. They are also more likely to be in a precarious financial condition prior to the event, which can be exacerbated by the difficulties emerging from network interruptions. The same point applies to businesses operating in the competitive retail and service sector whose financial stability is more likely to be jeopardized by supply chain disruptions (Tierney, 2007). Other characteristics such as the property ownership, the age of the business, whether the manager lives at his workplace, the indebtedness of the company, and the time relying on stocks have been tested but are not statistically significant in our models. However, model A suggests the age and indebtedness of businesses have a negative effect on resilience while the property ownership, its location as the ordinary residence of the owner and the length of time relying on stocks have positive effects. Such findings are in line with expectancies. However, for the age of the business, assumptions can differ: older businesses are more likely to engage in preparedness activities due to their experience with previous disasters, while younger businesses have a longer planning horizon, less organizational inertia and stronger resources that all together enhance their ability to cope with utility outages. 
Most pro-active adaptations seem to positively influence economic resilience although none of them is statistically significant in our models. Businesses that subscribe to business interruption insurances are already aware of the risks they encounter and voluntarily intend to broaden their insurance cover against those risks. Therefore, non-mandatory business interruption insurance may be considered as a proxy for engaging in preparedness activities and that is why insured businesses tend to be more resilient. Owning substitution solutions to the water network has a mixed effect on resilience. Although having a well contributes positively to resilience, other types of substitution solutions (e.g. water tank, rainwater collector) do not. An explanation stems from the type of water needs for which wells are used. Conversely to other solutions, most of the businesses that have a private well at disposal use water for production or sales, they are therefore by construction more sensitive to water shortages. However, using their well is likely to reduce the economic impacts they would suffer in case of water shortage which makes them all the more resilient, given their high pre-existing sensitivity. As for membership in professional groups, it is an indicator of the ability of a business to resort to professional solidarity. Model A shows that it is positively correlated with resilience, even though this effect is not statistically significant.

561

562

563

564

565

566

567

568

We investigate the effect of four reactive adaptations. Results show that the ability to modulate either working hours or production processes is a strong driver of resilience. Businesses that are able to make up the initial production loss by rescheduling operations and working extra hours once the service has been restored are less likely to suffer strong economic impacts in the long-run. Results of Model B suggest that flexibility in production processes increase the economic resilience of businesses by 11 points, all other things being equal. Using input substitution and implementing conservation actions (i.e. reducing water consumption) have both positive but not statistically significant effects on resilience.

Table 3. - Approximately here

\section{Discussion}

Any discussion of our results should start by reminding that the case study is a method validation and illustration case study, with no pretence of it representing the economic context of Martinique. That being said, even with the relatively limited and constrained damages assessed here (i.e. one network interruption with no ripple-effect on interrelated networks), results show that impacts of network disruptions could last over a month and cause significant losses to individual businesses. Measures of economic resilience validate the necessity to account for both the immediate economic impacts and the time span of the recovery process since businesses that suffer the higher economic impacts during shutdowns are not necessarily the ones suffering the higher long-term impacts. Results show that businesses are more resilient to DWNS than to ENS which is in line with the findings of Kajitani and Tatano (2009) and with intuitions. This result supports the validation of our indicator as a relevant measure of resilience. However, since the indicator is a relative measure, its scores are not supposed to be interpreted in absolute terms. They only aim to be compared relatively to the scores of other firms or other events. As a consequence, a score of 86 (mean economic resilience to DWNS) is not high per se but should only be considered as higher than a score of 75 (mean economic resilience to ENS).

Most results regarding the drivers of economic resilience are coherent with intuitions. In line with previous empirical studies, business size appears as a driver of resilience (Asgary et al., 2012; Chang \& Falit-Baiamonte, 2003; Rose et al., 2013; Tierney, 2007). However, when former studies justified the positive effect of business size on resilience with arguments relying interchangeably on turnover or 
number of employees, our specification allows demonstrating which attribute of business size actually fosters resilience, namely turnover rather than employees. Results also show that flexibility of working hours and production processes contribute largely to economic resilience (see Park et al. (2011) for a theoretical analysis of the influence of recapturing lost production on economic resilience). This is of particular interest considering that these adaptations may bring other co-benefits to businesses, even in the absence of any disasters (e.g. enhanced business continuity due to compressed work schedules, increased staff motivation with telecommuting). Therefore, they can be considered as no regrets adaptations (Hallegatte, 2009). Overall, our indicator seems to better capture the drivers of adaptive resilience than those of inherent resilience since none of the pro-active adaptations that were tested in the regressions emerged as statistically significant. In that respect, it is likely that it still integrates a sensitivity component that is not fully controlled for in the sensitivity indicator. The major challenge for defining an appropriate resilience indicator is indeed removing the sensitivity component from the economic impacts. This would allow focusing on the inherent and adaptive components of recovery. In our research however, some variables were missing to better define sensitivity such as the volumes of water needed per type of use for which the network is currently used by businesses. Essentially, specifying the sensitivity of a firm based on survey data will always remain difficult, because sensitivity relies on complex firm-specific production processes that cannot be accurately captured by closed-ended format surveys. Better characterizing business sensitivity is a challenge for future research.

From a methodological perspective, the use of a business survey allows reconstructing the likely impacts and associated behaviours of individual businesses during and after disasters. This enables assessing economic resilience ex-ante, even though some of its components are only manifest in the post-disaster phase. Also, it allows harmonizing the level of hazard and exposition for all businesses by setting identical hazard scenarios. However, resorting to an ex-ante business survey has certain limitations. It carries large uncertainties regarding the actual impacts that would be suffered by businesses in the event of a disaster since potential impacts are hypothetical and depend on how businesses perceive their own vulnerability and adaptive capacity to disaster risks. Such declared impacts are subject to strong cognitive and strategic biases (e.g. accounting for past experiences of natural disasters such as hurricane Dean). Moreover, the robustness of the results highly depends on the response rate and the representativeness of the sample. Here, the low response rate to the questionnaire is mainly due to the poor use of emails for business communications in Martinique. The length of the questionnaire (between 16 and 66 questions, depending on situations) and its filling time ( $27 \mathrm{~min}$ on average) do not appear as major obstacles to participation since out of the 119 respondents that did open the first page of the questionnaire, only $10 \%$ did not fill it entirely. Other possible explanations stem from the fact that scenarios depict events that are frequent on the island or that it is challenging to attract the interest of an audience when dealing with hypothetical future disaster situations, not focusing on one particular past event. In the field of natural disasters, most surveys targeting businesses were carried out in the aftermath of well-known past events. For instance, interrogating businesses on the impacts of the Northridge earthquake in California using a mail survey, Tierney (1997) reached a response rate of $23 \%$. However the survey was carried out twenty years ago, long before the mass use of questionnaire-based surveys and the competition it generates on the time availability of respondents. The mailing was followed up by telephone calls, and the survey was carried out sixteen months after the Northridge earthquake, dealing therefore with a real event still very present in the mind of businesses. Using a similar protocol, Brown et al. (2015) recently reached a 25\% response rate amongst businesses affected by the 2010/2011 Canterbury earthquakes in New Zealand. All in all, the effort to diffuse Internet questionnaires can outweigh the benefits of saving time to collect the data. 
With regards to the ability of the indicator to measure microeconomic resilience, it should be noted that building indicators always requires finding the appropriate balance between clarity and robustness, i.e. indicators have to be simple but not simplistic, accurate but not convoluted. In this way, our indicator offers a simplified view of a set of complex dynamics. It does not allow measuring the overall economic resilience of communities and its consequences in terms of aggregate output and welfare impacts. It only captures the microeconomic component of businesses' economic resilience, i.e. the ability of individual businesses to cope with a disaster and maintain activities under stress. Doing so, it considers each business as a single economic entity whose ability to cope with a shock depends on a set of non-hazard related factors. This means that macro-economic feedbacks and systemic effects stemming from relationships between producers and consumers within an economy are not accounted for. Moreover, the indicator tells nothing about non-economic dimensions of resilience such as those related to physical, human, cultural or environmental impacts. It can be comprehended as a complement to the resilience indicator developed by Rose (2009) on which we elaborate by adding both non-monetary and dynamic components to the measure of the variation of direct output as well as approximating the theoretical maximum percent change in direct output by a measure of the pre-existing vulnerability of businesses that we call sensitivity. As a result, even if the indicator is not capable of distinguishing different paths, it accounts for the dynamic evolution of recovery and impacts. Moreover, it relies on non-monetary metrics to capture non quantifiable impacts of natural disasters. As advocated by Hallegatte et al. (2011) and Schneider et al. (2000), the use of numeraires to assess indirect impacts avoids going through complex monetary valuations while broadening the scope of potential impacts beyond financial impacts that are rather limited. Because it is made of several subcomponents, our aggregated indicator is also highly dependent on the way variables and indicators are weighted. However, since weights are based on insights from the literature and not on local expert knowledge, our approach lacks an objective field-grounded weighting method.

Another limit pertains to the fuzzy distinction between pro-active adaptations and general characteristics. For instance, resorting to inventories can be considered as a characteristic that has nothing to do with anticipating the next hazard because it is a specificity of firms' operations or because it does not result from a conscious risk mitigation strategy. This fuzziness could be a pitfall for anyone willing to compare the influence of these two categories of explanatory variables on economic resilience. Moreover, the size of the sample did not allow undertaking detailed sector and spatial analysis of economic resilience although it would be useful to policy making and decision makers in order to pinpoint hotspots of poor resilience.

\section{Conclusion}

In a context of increasing impacts of natural disasters and high concentration of economic activities in dense urban environments, our research aimed at developing a scientifically sound operational measure of the economic resilience of individual businesses to lifeline service interruptions caused by natural disasters. We stabilized a conceptual framework pinpointing the peculiarities of resilience with respect to pre-existing vulnerability and adaptation. As such, we provided an understandable and useful analytical framework for both "risk" and "resilience" scientific communities whose definitions and overall understanding of these concepts often lack consistency. We then used this conceptual framework to build an operational indicator of the microeconomic resilience of individual businesses that we applied, as an illustration of its interest, to an urban community located in an overseas territory. Indicators of economic resilience are useful because they enable to empirically assess, map and compare resilience within a population of businesses over a given territory while analyzing the drivers of economic resilience, as illustrated in this paper. Moreover, they can also be used to adapt 
production functions developed in classical macroeconomic models in order to account for resilience of businesses and therefore provide more accurate assessments of the economic impacts of disasters.

The added-value of this research is threefold. First, it builds on previous work on resilience to elaborate a conceptual framework that highlights the multidimensional nature of economic resilience at the microeconomic level. This is of interest to identify the factors that determine the rebound capacity of businesses which is at the core of resilience, as opposed to vulnerability and adaptation. Second, it develops a methodology to measure the economic resilience of individual businesses using empirical data. The indicator that is developed addresses two important shortcomings regarding the measurement of individual economic resilience. It accounts for both market and non-market impacts of disasters and therefore enlarges the scope of impacts considered in resilience assessments. It also isolates pre-existing sensitivity to shocks from overall economic impacts and thereby allows comparing pattern of resilience across businesses according to their ability to absorb and respond to a shock, disregarding their pre-existing sensitivity to the shock. This avoids mistaking the root cause of the economic impacts. In doing so, it differentiates businesses that are little impacted because they are by essence little sensitive to the disaster from businesses that are little impacted because they are resilient. Third, it enables to compare economic resilience among firms or events and thereby identify the types of firms, sectors or geographical areas that are the most prone to suffer long-term damages from disasters. This is of prime interest to elaborate targeted policy recommendations for building resilient economies.

Understanding the drivers of resilience without mingling them with the drivers of sensitivity which is per se embodied in current business practices and has nothing to do with its ability to cope with upcoming events, will help develop efficient risk reduction policies targeted at businesses that effectively lack resilience rather than businesses that are solely sensitive to the disaster but potentially very well prepared to its effects. Our results illustrate the challenge of removing all sensitivity components from resilience in an empirical exercise.

Although results should be used with caution, the application of our methodology to a case study in the French West Indies shows that it is suited to test assumptions empirically. It confirms the essential role of business size on resilience differentiating a positive effect of turnover on resilience and a negative effect of the number of employees. Flexibility in working hours and production processes also showed to be significant drivers of resilience.

Further research could investigate more thoroughly the inherent component of resilience. This is an important issue since ex-ante risk reduction strategies would be more effective focusing on fostering the resilience already built in business functioning than on anticipating the best ways of assisting businesses during disasters when resources are scarce and the capacity to act is limited. Observing the paths and dynamics that businesses follow when recovering would be also very instructive and should be a perspective for future research in the field of economic resilience. Detailed examination of the double counting issues when compiling resilience indicators such as the one suggested in this paper is also an important challenge for the operationalization of the resilience concept. In addition, getting a larger dataset would allow investigating the effect of more variables (e.g. economic sector, geographic location, supplier diversification, production of perishable goods, previous disaster experience) and explore the substitution effect between insurance and adaptation in order to better understand firm strategies with regard to risk reduction. Ultimately, results aim at feeding broader resilience assessments that account not only for individual resilience but also for both hazard characteristics and systemic effects on overall economies.

\section{Acknowledgements}


This work was supported by BRGM. The authors gratefully acknowledge the Communauté d'Agglomération du Centre de la Martinique, the Chambre de Commerce et d'Industrie and the Chambre des Métiers et de l'Artisanat for their help in disseminating the questionnaire. We thank Daniel Monfort-Climent for very helpful exchanges on an earlier version of this paper as well as JeanDaniel Rinaudo and Bastien Colas for discussions on the various components of resilience and Aude Nachbaur for her useful help in understanding the peculiarities of the Martiniquese economy. We also acknowledge the very useful and relevant contributions of three anonymous reviewers. All errors and omissions remain our responsibility.

\section{References}

Adger W. N. (2006) Vulnerability. Global Environmental Change 16, 268-281.

Alesch, D. J., Holly, J. N., Mittler, E., \& Nagy, R. (2001). Organizations at risk: What happens when small businesses and not-for-profits encounter natural disasters. Public Entity Risk Institute.

Alexander D. E. (2013) Resilience and disaster risk reduction: an etymological journey. Nat Hazards Earth Syst Sci 13, 2707-2716.

André C., Monfort D., Bouzit M., Vinchon C. (2013) Contribution of insurance data to cost assessment of coastal flood damage to residential buildings: insights gained from Johanna (2008) and Xynthia (2010) storm events, Nat. Hazards Earth Syst. Sci., 13, 2003-2012.

Angell E., Stokke K. B. (2014) Vulnerability and adaptive capacity in Hammerfest, Norway. Ocean \& Coastal Management 94, 56-65.

Asgary A., Anjum M. I., Azimi N. (2012) Disaster recovery and business continuity after the 2010 flood in Pakistan: Case of small businesses. International Journal of Disaster Risk Reduction 2, 46-56.

Aulong S., Chaudhuri B., Farnier L., Galab S., Guerrin J. (2011) Are South Indian farmers adaptable to global change? A case in an Andhra Pradesh catchment basin. Regional Environmental Change, Springer Verlag, 2012, 12 (3), pp.423-436.

Babre S., Bolliet A., Breuil P., Goenaga M., Jamet C., Martin X., Paul S., Revial T. (2007) Rapport sur l'évaluation des dommages provoqués par l'ouragan "DEAN" en Martinique et en Guadeloupe. République Française. Available at www.interieur.gouv.fr/content/download/1634/.../07-048-01_Cyclone_Dean.pdf

Bassett T. J., Fogelman C. (2013) Déjà vu or something new? The adaptation concept in the climate change literature. Geoforum 48, 42-53.

Bergström J., van Winsen R., Henriqson E. (2015) On the rationale of resilience in the domain of safety: A literature review. Reliability Engineering \& System Safety, 141:131141.Biagini B., Bierbaum R., Stults M., Dobardzic S., McNeeley S. M. (2014) A typology of adaptation actions: A global look at climate adaptation actions financed through the Global Environment Facility. Global Environmental Change 25, 97-108.

Birkmann J. (2006) Measuring Vulnerability to Natural Hazards- Towards Disaster-Resilient Societies. United Nations University Press responses: the MOVE framework. Natural Hazards 67, 193-211. 
Boarnet M. G. (1996) Business Losses, Transportation Damage and the Northridge Earthquake. University of California Transportation Center. UC Berkeley: University of California Transportation Center.

Brown C., Stevenson J., Giovinazzi S., Seville E., Vargo J. (2015) Factors influencing impacts on and recovery trends of organisations: evidence from the 2010/2011 Canterbury earthquakes. International Journal of Disaster Risk Reduction 14, Part 1, 56-72.

Brozović N., Sunding D. L., Zilberman D. (2007) Estimating business and residential water supply interruption losses from catastrophic events. Water Resources Research 43, n/a-n/a.

Chang S. E., Falit-Baiamonte A. (2003) Disaster vulnerability of businesses in the 2001 Nisqually earthquake. Environmental Hazards, 4, 59-71.

Chen Z., Rose A., Prager F., Chatterjee S. (2015) Economic Consequences of Aviation System Disruptions: A Reduced-Form Computable General Equilibrium Analysis. Available at: http://papers.ssrn.com/sol3/papers.cfm?abstract $\mathrm{id}=2692177$

Cox A., Prager F., Rose A. (2011) Transportation security and the role of resilience: A foundation for operational metrics. Transport Policy 18, 307-317.

Darnhofer I., Fairweather J., Moller H. (2010) Assessing a farm's sustainability: insights from resilience thinking. International Journal of Agricultural Sustainability 8, 186-198.

Eidsvig U. M. K., McLean A., Vangelsten B. V., Kalsnes B., Ciurean R. L., Argyroudis S., Winter M. G., Mavrouli O. C., Fotopoulou S., Pitilakis K., Baills A., Malet J. -., Kaiser G. (2014) Assessment of socioeconomic vulnerability to landslides using an indicator-based approach: methodology and case studies. Bulletin of Engineering Geology and the Environment 73, 307-324.

Fankhauser S., Smith J. B., Tol R. S. J. (1999) Weathering climate change: some simple rules to guide adaptation decisions. Ecological Economics 30, 67-78.

Folke C. (2006) Resilience: The emergence of a perspective for social-ecological systems analyses. Global Environmental Change 16, 253-267.

Fussel H., Klein R. J. T. (2006) Climate Change Vulnerability Assessments: An Evolution of Conceptual Thinking. Climatic Change 75, 301-329.

Gallopín G. C. (2006) Linkages between vulnerability, resilience, and adaptive capacity. Global Environmental Change 16, 293-303.

Hallegatte, S. (2008). An adaptive regional input-output model and its application to the assessment of the economic cost of Katrina. Risk analysis, 28(3), 779-799.

Hallegatte S. (2009) Strategies to adapt to an uncertain climate change. Global Environmental Change $19,240-247$.

Hallegatte S., Przyluski V. (2010) The economics of natural disaster, CESifo Forum 2 06/2010.

Hallegatte S., Henriet F., Corfee-Morlot J. (2011) The economics of climate change impacts and policy benefits at city scale: a conceptual framework. Climatic Change 104, 51-87.

Henriet F., Hallegatte S. (2008) Assessing the Consequences of Natural Disasters on Production Networks: A Disaggregated Approach. FEEM Working Paper. No. 100.2008.

Hess J. J., Malilay J. N., Parkinson A. J. (2008) Climate Change: The Importance of Place. American Journal of Preventive Medicine 35, 468-478. 
811 Hosseini S., Barker K., Ramirez-Marquez J. E. (2016) A review of definitions and measures of system resilience. Reliability Engineering \& System Safety, 145:47-61.

IPCC. (2012) Managing the Risks of Extreme Events and Disasters to Advance Climate Change Adaptation. A Special Report of Working Groups I and II of the Intergovernmental Panel on Climate Change [Field, C.B., V. Barros, T.F. Stocker, D. Qin, D.J. Dokken, K.L. Ebi, M.D. Mastrandrea, K.J. Mach, G.-K. Plattner, S.K. Allen, M. Tignor, and P.M. Midgley (eds.)]. 582 pp.

IPCC. (2014) Climate Change 2014: Impacts, Adaptation, and Vulnerability. Part A: Global and Sectoral Aspects. Contribution of Working Group II to the Fifth Assessment Report of the Intergovernmental Panel on Climate Change [Field, C.B., V.R. Barros, D.J. Dokken, K.J. Mach, M.D. Mastrandrea, T.E. Bilir, M. Chatterjee, K.L. Ebi, Y.O. Estrada, R.C. Genova, B. Girma, E.S. Kissel, A.N. Levy, S. MacCracken, P.R. Mastrandrea, and L.L. White (eds.)].Cambridge University Press, Cambridge, United Kingdom and New York, NY, USA, 1132 pp. .

Kajitani Y., Tatano H. (2009) Estimation of Lifeline Resilience Factors Based on Surveys of Japanese Industries. Earthquake Spectra 25, 755-776.

Kelly P. M., Adger W. N. (2000) Theory and Practice in Assessing Vulnerability to Climate Change andFacilitating Adaptation. Climatic Change 47, 325-352.

Kroll C., Landis J., Shen Q., Stryker S. (1991) The Economic Impacts of the Loma Prieta Earthquake: A Focus on Small Business. Berkeley Planning Journal 5(1).

Linkov, I., Bridges, T., Creutzig, F., Decker, J., Fox-Lent, C., Kröger, W. et al. (2014). Changing the resilience paradigm. Nature Climate Change,4(6), 407-409.

Manyena B., O'Brien G., O'Keefe P., Rose J. (2011) Disaster resilience: a bounce back or bounce forward ability? Local Environment 16, 417-424.

Manyena S. B. (2006) The concept of resilience revisited. Disasters 30, 434-450.

Menoni S., Pergalani F., Boni M. P., Petrini V. (2002) Lifelines earthquake vulnerability assessment: a systemic approach. Soil Dynamics and Earthquake Engineering 22, 1199-1208.

Oxford Metrica (2015) The 2015 FM Global Resilience Index. 2015 Annual Report.

Papathoma-Köhle M., Kappes M., Keiler M., Glade T. (2011) Physical vulnerability assessment for alpine hazards: state of the art and future needs. Natural Hazards 58, 645-680.

Park, J., Cho, J., \& Rose, A. (2011). Modeling a major source of economic resilience to disasters: recapturing lost production. Natural Hazards, 58(1), 163-182.

Park S. E., Marshall N. A., Jakku E., Dowd A. M., Howden S. M., Mendham E., Fleming A. (2012) Informing adaptation responses to climate change through theories of transformation. Global Environmental Change 22, 115-126.

Pascale S., Sdao F., Sole A. (2010) A model for assessing the systemic vulnerability in landslide prone areas. Natural Hazards and Earth System Science 10, 1575--1590.

Pelling M., Uitto J. I. (2001) Small island developing states: natural disaster vulnerability and global change. Global Environmental Change Part B: Environmental Hazards 3, 49-62. 
Pelling M., Özerdem A., Barakat S. (2002) The Macro-economic Impact of Disasters", Progress in Development Studies 2, 283-305.

Pelling M. (2010) Adaptation to climate change: from resilience to transformation. Routledge.

851

852

853

854

855

856

857

858

859

860

861

862

863

864

865

866

867

868

869

870

871

872

873

874

875

876

877

878

879

880

881

882

883

884

885

886

887

Reghezza-Zitt, S. Rufat, G. Djament-Tran, A. Le Blanc, S. Lhomme (2012) What resilience is not: uses and abuses, Cybergeo: European Journal of Geography

Rose A. Z. (2004) Defining and measuring economic resilience to disastersnull. Disaster Prev and Management 13, 307-314.

Rose A. Z., Liao S. (2005) Modeling Regional Economic Resilience to Disasters: A Computable General Equilibrium Analysis of Water Service Disruptions. Journal of Regional Science 45, 75-112.

Rose A. Z. (2009) Economic Resilience to Disasters. CARRI Research Report 8.

Rose A. Z., Brock B. S. (2010) Total Economic Consequences of Terrorist Attacks: Insights from 9/11. Peace Economics, Peace Science and Public Policy 16.

Rose A. Z., Krausmann E. (2013) An economic framework for the development of a resilience index for business recovery. International Journal of Disaster Risk Reduction 5, 73-83.

Saunders W. S. A., Becker J. S. (2015) A discussion of resilience and sustainability: Land use planning recovery from the Canterbury earthquake sequence, New Zealand. International Journal of Disaster Risk Reduction 14, Part 1, 73-81.

Schneider S. H., Kuntz-Duriseti K., Azar C. (2000) Costing nonlinearities, surprises and irreversible events. Pacific and Asian Journal of Energy 10(1):81-91.

Sedan O., Negulescu C., Terrier M, Roull'e A., Winter T. (2013) Armagedom - A Tool for Seismic Risk Assessment Illustrated with Applications. Journal of Earthquake Engineering, Taylor \& Francis, 2013, 17 (2), pp.253-281.

Smit B., Burton I., Klein R. T., Wandel J. (2000) An Anatomy of Adaptation to Climate Change and Variability. Climatic Change 45, 223-251.

Smit B., Wandel J. (2006) Adaptation, adaptive capacity and vulnerability. Global Environmental Change 16, 282-292.

Tierney K. J. (1997) Business Impacts of the Northridge Earthquake. Journal of Contingencies and Crisis Management 5, 87-97.

Tierney K. J. (2007) Businesses and Disasters: Vulnerability, Impacts, and Recovery. Handbook of Disaster Research. 275-296.

Timmerman P. (1981) Vulnerability, resilience and the collapse of society: a review of models and possible climatic applications. Environmental Monograph no. 1,

Tompkins E. L., Eakin H. (2012) Managing private and public adaptation to climate change. Global Environmental Change 22, 3-11.

Turner B.L. (2010) Vulnerability and resilience: Coalescing or paralleling approaches for sustainability science? Global Environmental Change 20, 570-576.

Turner B. L., Kasperson R. E., Matson P. A., McCarthy J. J., Corell R. W., Christensen L., Eckley N., Kasperson J. X., Luers A., Martello M. L., Polsky C., Pulsipher A., Schiller A. (2003) A framework for vulnerability analysis in sustainability science. Proceedings of the National Academy of Sciences 100, 8074-8079. 
UNFCC. (1992) United Nations Framework Convention on Climate Change. United Nations, FCCC/INFORMAL/84 GE.05-62220 (E) 200705.

890 UNISDR. (2005) Framework for Action 2005-2015. Building the Resilience of Nations and 891 Communities to Disasters.

892 Vincent K. (2007) Uncertainty in adaptive capacity and the importance of scale. Global Environmental 893 Change 17, 12-24.

894 Webb G. R., Tierney K. J., Dahlhamer J. M. (2002) Predicting long-term business recovery from 895 disaster: a comparison of the Loma Prieta earthquake and Hurricane Andrew1. Global Environmental 896 Change Part B: Environmental Hazards 4, 45-58.

\section{Appendix. Data collection}

The two-step data collection process consisted in (i) preliminary interviews and (ii) the dissemination of a business internet survey.

\section{$\underline{\text { Preliminary interviews }}$}

902

903

904

905

906

907

908

909

910

911

912

913

914

915

916

917

918

919

920

The first stage started with a first series of interviews (10) with local decision makers and natural hazard experts selected for their concrete knowledge and global vision of the stakes related to the vulnerability and resilience of businesses to natural risks in the case study among which local policymakers, state representatives, network managers and natural hazard scientists. These interviews allowed better understanding the peculiarities of the Martiniquese context and the exposure of its economic agents to natural risks. It also helped fine-tuning the design of the next steps of the research in light of empirical information gathered from local stakeholders. A second series of face-to-face interviews was carried out with a sample of twenty business managers located within the perimeter of the Urban Community of Central Martinique. These semi-directive interviews aimed to characterize how network interruptions impact firm activities (e.g. which technical, economic and organizational processes are likely to be affected at firm level), identify the set of adaptation measures implemented by businesses to cope with these impacts/recover from the shock, and identify the factors likely to have an influence on the economic resilience of businesses to natural risks. The selection of interviewed businesses from the business contact database of the UCCM was realized with a stratified and quota sampling approach. Businesses were differentiated according to three stratifying variables: economic sector, city location and number of employees. The sample was then built so as to match the current share of each of these variables in the Martiniquese economy. Results of this qualitative analysis were then used in the second stage of our study for the design of a web questionnaire that was addressed to a large sample of businesses.

\section{Business internet survey}

The questionnaire is divided into four parts: (1) the general characteristics of the business, including its economic sector, annual turnover, current number of employees, geographic location, use of insurance and ownership of business property; (2) the dependence of its activities to lifeline services provided by critical networks and infrastructures, including questions on the operational and economic impacts that businesses sustain as a result of lifeline service interruptions and on preparedness measures undertaken both before and following an interruption; (3) the exposure of business activities to natural hazards, including events that may have impacted the business in the past and their impacts on its operation and revenue; and (4) the individual socio-economic characteristics of the respondent. The overall questionnaire consists of 83 questions, of which 34 are mandatory and 39 are conditional 
on answers provided to previous questions (some questions are both conditional and mandatory). All in all, the backbone of the questionnaire includes 44 questions, of which 16 are mandatory. Since some sets of conditional questions depend on a unique previous question, there is no case in which a respondent would be asked to answer to each of the 83 questions. It is mostly made of closed-ended questions and multiple choices questions, although a few open-ended questions are also included in order to gather detailed answers on specific aspects and offer respondents the opportunity to freely express their views on the topic.

The questionnaire is introduced by a few pedagogic lines on the research topic and a description of the aim and scope of the questionnaire. A particular attention was paid to highlighting the contribution of potential respondents to a singular research effort so as to enhance their motivation to participate in the survey. To maximize the response rate, a lottery incentive was also added to the survey. Respondents that would entirely fill the questionnaire were offered to participate in a lottery selecting randomly 30 winners of a Guide to the Geological Curiosities of Martinique whose retail price is $19 €_{2015}$.

The survey was broadcasted exclusively on the internet. It was distributed to individual businesses located within the perimeter of the UCCM during the summer of 2015. The distribution process was three-fold and consisted in e-mailing a short paragraph introducing the objective, the content and the link to the survey to individual businesses. First, the questionnaire was sent to businesses whose email addresses were registered in the business contact databases of three local public institutions: the UCCM, the Regional Chamber of Commerce and Industry and the Regional Chamber of Trade and Craft. In order to benefit from the long-term trustful relationship linking these institutions to their members, the three entities were asked to send themselves the questionnaire to their members. Second, the main business associations exercising in Martinique were asked to transfer the link to the survey to their members. The use of sectorial and local business associations to relay the questionnaire aimed at fostering the response rate by increasing the credibility of the approach among business managers. It also allowed targeting a wider list of businesses so as to broaden the scope of the sample. Based on public data, a particular attention was paid to targeting similarly each economic sector to ensure that targeted businesses be representative of the general structure of the Martiniquese economy. The third approach consisted in broadcasting and publicizing the survey on social media. Specific pages promoting both the survey and the RESILCITY project were created on Facebook, Viadeo and LinkedIn. Each page encouraged business managers to click on a link to open the questionnaire. Moreover, on Facebook, an advertising campaign was carried out in order to promote the survey to a specific audience consisting in individual profiles matching two criteria: the geographic location of the individual (Martinique) and its general interests (business, trade, business, sales and entrepreneurship). The campaign made visible a small box promoting the questionnaire on the Facebook pages of about 12500 profiles matching these criteria. Two series of emails were sent to businesses by public institutions and business associations in July and September 2015. Similarly, the advertising campaign took place both in July and in September 2015. 